\title{
Gorkhas of Assam and Their Movement for Constitutional Status
}

\author{
Surya Newar \\ Asst Prof. Dept of Pol Science, Kapili College, Kheroni, K/A, Assam, India. Pin. 782448
}

\begin{abstract}
The movement for distinct Nepali identity in India first originated in Darjeeling under the banner of the All India Gorkha League (1943) under the stewardship Dambar Sing Gurung. Shortly after its foundation the All India Gorkha League (AIGL) started organizing the Nepalese People living scatteredly all over the country. The then province of Assam was also not left unbind by the wave of inculcating some of the distinctive identity among the Nepalese. It resulted in the formation of the Assam Provincial Gurkha League in 1944 at Shillong the then capital of Assam.

The Assam Provincial Gorkha League (AIGL) - a provincial banner of the parent outfit appeared to be following the cluster of demands chalked in later. The demand for official recognition to Nepalese as a minority community was important in this context. In the similar manner, the APGL went on raising a plethora of demands and grievances which are more or less identical and as such many a time both the AIGL and APGL concertedly participated in a movement like constitutional recognition of Nepali language. But surprisingly the AIGL leadership in 1955 officially declared the conversion of AIGL as a full-fledged political party. Being disgraced with such conversion the APGL leadership decided to disassociate from the AIGL and got their own name and style as Assam Gorkha Sammelan. Since then Assam Gorkha Sammelan has been working independently confining its activities within the state of Assam. Of course, in the event of raising a common issue the AGS as prepared to join hands with All India level Nepali organization. For instance, the demand for the inclusion of Nepali language to the eighth schedule of the constitution of India. In this language movement the Nepalese participated with full strength and sweat along with the All India Nepali Bhasa Samiti (1972) which ended in 1992 when Nepali language was incorporated into the constitution.

The Nepalese settled permanently in Assam ever since the British occupation has become a part and parcel of the greater Assam and Assamese society. With the growth of their numerical strength, and democratization of political system and universalisation of education, there emerged an educated elite among the Nepalese who realized their backwardness and underdeveloped. As a measure to solve their multifold and multifaceted demand, like other ethnic group the Nepalese also formed their organizations. Among

these the Assam Gorkha Sammelan and All Assam Gorkha Students' emerged as a leading organizations to champion the cause of maintaining distinct identity as a means of accelerating the pace of development.
\end{abstract}

\section{Introduction:}

The Nepalese of Assam faced a lot of problem after independence. To fulfill their demands the Gorkhas of Assam under the banner of organizations such as Assam Gorkha Sammelan (AGS), All Assam Nepali Students' Union now All Assam Gorkha Students Union etc have placed various demands to the Government of Assam as well as India. Such demands are to include Nepalese in to the minority class, Schedule caste and Schedule Tribe, protect them in tribal belt and block, introduce Nepali subject in the UG and Post Graduate level, satellite council to the Nepalese and so on.

The seed of movement for distinct identity of the Nepalese in India was first sown in Darjeeling of west Bengal. The Gorkhas/Nepalese ${ }^{1}$ became increasingly conscious to protect and preserve their distinct identity and thereby to ensure all round development on the eve of the independence of the country. The All India Gurkha League (AIGL),1943 pleaded to recognize the Nepalese as a 'minority community' as a measure of maintaining distinct identity, the integration of Nepali inhabiting areas of India into a single whole. As such, the AIGL convincingly pleaded for the integration of Darjeeling and Jalpaiguri districts of west Bengal into $\mathrm{Assam}^{2}$ in a memorandum submitted to the Governor General of India in may, 1947. The Nepali elite of Darjeeling, perhaps, thought that the integration of these territories into Assam might facilitate them to consolidate their numerical strength which would help them to be united and raised the demands.The Gorkha/Nepali elites, however, well conceived that they must increase the contour of organization in order to protect their interests in India. In view of this, they started mobilizing Nepali Speaking population living in other part of the country seeking support for their pressing demand. In this way, the Assam Provincial Gorkha League was formed in 1944 at the initiative of the AIGL with similar aims and objectives. The Assam provincial Gorkha League extended its full-fledged backing and support to the demands of the AIGL and in its maiden annual conference held at Gauhati on 31 december 1946 and $1^{\text {st }}$ January 1947, unanimously resolved: 
The three million Gorkhas, through sharing common tradition with rest of the Indian nevertheless, have a language, culture and tradition of their own; thus forming a distinct community in India. Hence, this session of the Assam provincial Gurkha league demands the constituent Assembly to recognize the Gorkhas Statutorily as a minority community of India.$^{3}$

Notwithstanding, the Gorkha/Nepali elite of Assam started demanding the inclusion of Nepalese into the list of Other Backward Classes (OBC) after the independence of the country. They realized that it was necessary to get the Nepalese recognized as a backward class in order to remove their socio-economic backwardness and elevate their overall status. Keeping this in mind Dalbirsingh Lohar, the lone Nepali member moved a resolution in the Assam legislative Assembly (hereinafter the ALA) which maintained:

In view of appalling illiteracy and poverty of the bulk of the people of Gurkha

Community in Assam, this Assembly is of the opinion that the Government of Assam

do move to the Government of India if necessary to recognize the said community as a backward. ${ }^{4}$

At the same time, a Backward Class Commission was constituted by the Government of India in 1953 under the chairmanship of Kaka Kalelkar in order to investigate the socio-economic conditions of different Communities and recommend them as the backward communities. In view of this, a memorandum was submitted to the Commission clamoring for the inclusion of the Nepalese into the list of Other Backward Classes (OBC) by the Nepali elite of Assam also. Mention may be made here that after considering the report of the Commission, the task of preparing the list of backward classes was entrusted in the hands of the respective state government as the same failed to carryout the accountability as required. It is a matter of grave concern to the Gorkhas/Nepalese of Assam that they were not included in the list of backward classes, unfortunately by the Government of Assam till the middle of the sixties of the last century. However, a few castes of the Gorkhas/Nepalese were given the status of Other Backward Classes in $1955,{ }^{5}$ which was a matter of rejoice to the Gorkhas of Assam in particular after the independence.

Mention may be made here is that there is social hierarchy in the caste system of the Nepali Community like any other Hindu castes system. In fact, the Nepalese belonging to Tibeto-Mongoloid group such as the Rais, The Limbus, the Tamangs, the Gurungs, the Mogors, the Bhujels, the Sarkis, the Damais, the Kamis, the Gaines are much more backward than the Indo-Aryn groups like the Brahmis, (including Upadhaya, khanal, Gauttam, Dahal, Sarmah, Timsina, Neupane), Chetries, the Khatrias, the Thakuris and the Ranas, the Newars. The Tibeto -Mongoliod groups of the Gorkha/Nepali community are considered as low caste and they were included in the list of 'Other Backward Classes' (OBC). How ever, it did not console to the Nepali elite and they felt that it was insufficient for ascertaining all-round, development by mere inclusion of a few castes in the list of OBC. Therefore, the Gorkha elite pleaded for the inclusion of backward castes of the Nepali Community particularly belonging the Tibeto-Mongloid stock into the list of scheduled Tribes. Hence, a memorandum was submitted by the most articulate organization of the Gorkhas/Nepalese named Assam the Gorkha Sammelan to the government of India on $24^{\text {th }}$ July 7 1968, demanded:

On behalf of the Indian Nepalese in general and the Nepalese of Assam in

particular, it is requested that due consideration be made for their miserable plight to

include the Nepalese as a Tribes of the Constitution so that they may get scope for

coming up to the level of their compatriot in course of time and be able to share the

sorrow and happening of the land under the same roof on equal footing with the rest of citizens of the country. ${ }^{6}$

It is to mention here that the demand of the Gorkha/Nepali elite was not limited only with the recognition of backward castes of the Nepalese community as Scheduled Tribe but also pleaded for the recognition of socially depressed sections of the Nepalese as Scheduled caste. They believed that the socioeconomic backwardness of the Tibeto Mongoloid group of the Nepalese could not be eradicated unless and until they were recognized as Scheduled castes and scheduled tribes. Indeed, there were some justifications of their argument that though similar castes of the Nepalese were being recognized as the Scheduled castes and Scheduled Tribes (SC \& ST) in other states of India particularly in West Bengal and Sikkim. Obviously, therefore, the Nepali elite developed a sense of deprivation, discrimination as well as humiliation because the same benefits were not extended to their counterparts in Assam.

Another articulate organization of the Nepalese of Assam namely the All Assam Nepali Students' Union (hereinafter the AANSU) founded in 1976, has also been very much concerned about the various problems of their community. They realized that the Nepalese in Assam were more backward than other backward communities of the State, for which they felt the need of certain constitutional safeguards so as to remove their backwardness. In view of this, like the AGS, the AANSU also put forward similar demands and 
grievances before the concerned authority and as such a memorandum was submitted to the Prime Minister of India on $24^{\text {th }}$ July, 1980 by the AANSU and logically pleaded:

The Nepalese of India are Hindu by religion and as they inherit the virtues and vices of the great Hindu Society. They are traditional backward and neglected castes and Tribes including 'untouchables' have their counterparts among the Nepali speaking people also, but they are not enlisted as Scheduled Castes and Scheduled Tribe. For example, Domoi, Kami, Gainay, Bhujel and Sarki should be enlisted as Scheduled Castes. Similarly, Limbu, Rai, Mogar, Gurung, Bhutia, Lepcha etc are the counterparts of the recognized Scheduled Tribes of other Hindus. The list is not exhaustive. We urge upon the Government to prepare the list of the Nepali- speaking social groups who may be recognized as Scheduled Caste and Scheduled Tribes after consulting the various social organizations like Assam Gorkha Sammelon, All India Nepali Bhasa Samiti etc. ${ }^{7}$

It appears to the minds of a section of the Gorkha/Nepali elite that the Gorkhas/Nepalese were squarely lagging behind as a whole irrespective of their caste status. They, therefore, even pleaded for the inclusion of upper castes of the Nepalese Community into the list of other Backward Classes in the middle of the eighties of the twentieth century. Accordingly, the AGS unanimously adopted a resolution demanding the recognition of upper castes of the Nepalese Community as the OBC, in its $18^{\text {th }}$ Annual Conference held at Margherita (the then undivided Dibrugarh District) on December 30, 1984. ${ }^{8}$ It was realized by the Gorkha elites that their population was not at per with the development of other population of the state and it would not be possible until and unless they were constitutionally safeguarded.

In this way, the Nepali elite, with the growing consciousness and organizational strength began to urge upon the government to fulfill their demands in an bid to establish their community into a rightful place in the contemporary socio-economic scenario of state. Mention may be made that like Nepalese, other ethnic groups of the state also formed their respective organization for the maintenance of distinctive sociocultural identities. It is to be mentioned here that the leaders of different ethnic groups realized for a common political platform to get fulfilled their multifaceted demands in 1980s instead of fighting in single platform. In order to safeguard the interest of depressed classes, the leaders of organizations such as the All Tai-Ahom Students' Union, All Assam Tribal Union, All Assam Chutiya Sanmilan and Jharkhand Sangram Parishad floated an organization under the name and style of the United Reservation Movement Council of Assam (URMCA) in 1986. ${ }^{9}$ The AANSU became a constituent organ of the URMCA since their demands got a place to find out a solution in the charter of demands of later.

Furthermore, the Nepali elite raised another very important demand of the Nepalese Community was the demand for constitutional recognition of 'Nepali language' under eighth schedule of the constitution of India. It is known to all that the constitution of India has guaranteed the right to preserve cultivates and promotes the language and culture of different communities. In consonance with this the Nepalese was too desired to preserve their socio-cultural heritage including the language as a measure of maintaining distinct identity. They deeply believed that the constitutional recognition of Nepali language was quite imperative for the maintenance of Nepali identity. Nevertheless, it is desirable to know its historical legacy in order to have a better understanding of the linguistic demand of the Nepalese. It may be noted that after independence especially when the provinces were to be reorganized on the basis of linguistic principle, the Nepali elite of Darjeeling also put forward the demand for constitutional recognition of their language so that they might have a separate state in the days ahead on the basis of distinct Nepali language. Thus, like the demand for 'Minority Status' the linguistic demand of the Nepalese too first started in other parts of India, more particularly, in Dehradoon of Utter Predesh. ${ }^{10}$ Of course, the leadership of the linguistic movement of the Nepalese was premeditatedly shifted to Darjeeling in the late fifties of the last century, when the district Committee of the AIGL adopted a resolution demanding constitutional recognition of Nepali language in 1959. The Gorkhas of India were encouraged by a renowned linguistic writer Suniti Kumar Chatterjee. The Gorkha elite, while justifying their demand, very often referred to the remark made by him who maintained in his famous book "Languages and Literatures of Modern India" (1956) other Indian languages are to be added in this (Eighth) schedule following the wishes of their speakers and their importance i.e. Sindhi and Nepali ${ }^{11}$. This kind of remarks invariably encouraged the Nepali elite to purse their linguistic demand which they thought, would ensure the maintenance of their distinct identity in India. Furthermore, the constitutional recognition of Sindhi language in 1967 made the Nepali elite more aggrieved and assertive of their linguistic demand. Thus, in order to popularize and mobilize their people in a bigger way the elites decided to form a separate organization specially to pressurize the linguistic demand the All India Nepali Bhasa Samiti (hereinafter the AINBS) on January 31, 1972 at Darjeeling. This way, the linguistic movement of the Nepalese in India assumed greater significance with the formation of the AINBS which thenceforth spearheaded the linguistic movement of the Nepalese in India. At the same time, it was felt by the Gorkha Leadership that the Gorkhas of other part of the 
country need to be vigorously mobilized and actively involved in order to fulfill there linguistic demand. Thus, the AINBS formed its branches in other Nepali-inhabiting parts of the country including Assam in a bid to strengthen the organizational capacity for the cause of the constitutional recognition of Nepali language under eighth schedule of the Indian constitution.

The Gorkha leaders of Assam were encouraged under the influence of AINBS. As such they began to mobilize their community in the territorial domain of Assam for the fulfillment of their linguistic demand. They considered the recognition of Nepali language as one of the fundamental criteria for establishing the community into a rightful place. Accordingly, the AGS in a resolution adopted in the $13^{\text {th }}$ Annual Conference held at Tirap of the then Dibrugarh District on April 28, 1968 asserted that for the development of cultural heritage it is necessary to include Nepali language into Eighth schedule of the

Constitution of India. ${ }^{12}$ Apart from in order to justify and legitimize their demand, the Nepali elite of Assam pleaded that Nepali language is the mother- tongue of the Nepalese who constituted a sizeable number of population of the country. Thus, the AGS submitted a memorandum to the prime minister of India at Shillong on January 20, 1972 and strongly pleaded:

Nepali is a language which is spoken by nearly 5 millions of Indian Nepali citizens and over one lakh of defence and security personnel leaving aside hundred and thousands of other community people such as Lepchas and others who are also speaking this language. It has a sufficiently advanced literature, rich and very ancient culture and can rightly claim to deserve recognition as a major Indian language. In the opinion of eminent linguist like Suniti Kumar Chatterjee Nepali is one of the fifteen major Indian languages. Being in the main lineage of Sanskrit it is very closely related to Hindi, Bengali, Assamese, Marathi, and other like Bihari of Indo-European Group We, therefore, urge upon your benign self to recognize Nepali language as one of the major languages of India and include it in the Eighth Schedule of the Constitution of India. ${ }^{13}$

In this way, the Gorkha elite realized that the Nepali language traced its origin to Sanskrit for which there was a great deal of similarity with other recognized languages in India. It also appeared to them that the Nepali language was equally advanced and a rich language. Further more, while pursuing their linguistic demand the Nepali elite went on arguing that Nepali was introduced as an official language in the District of Darjeeling, recognized and introduced as a Major Indian Language (MIL) in the universities at Calcutta, North Bengal, Bhagalapur, Patna , Banaras, Gauhati and Dibrugarh. Likewise they referred to the Legislative Assemblies of West Bengal, Tripura and Sikkim which had passed resolutions to this effect. Considering all these they believed that the Government of India might be sympathetic towards the fulfillment of their long standing linguistic demand. In a memorandum submitted to the Prime Minister of India on July 24, 1990 the AANSU expressing likewise sentiment maintained:

That the Nepali-Speaking people of India have a long standing grievance, viz non- fulfillment of their legitimate demand for the inclusion of the Nepali language in the Eighth Schedule of the constitution. After the last Lok-Sabha election, Indian Nepalese have entertained the hope that this just and legitimate demand of theirs would be fulfilled soon. We, therefore, urge upon the Government to take necessary steps towards the constitutional recognition of the Nepali language, a language spoken by more than 50 lakh of Indians. ${ }^{14}$

It is interesting to note that the Nepalese of Assam got a positive look even when a section of the Assamese intelligentsia seemed to be sympathetic towards the aforesaid pressing demand of the Nepalese community of India. For instance, Deba Prasad Boruah ,the former Vice-Chancellor of Gauhati University pleaded :

Language is a legitimate demand and it is necessary for the sake of unity and integrity of the country. The recognition and inclusion of Nepali language into the Eighth schedule of the constitution will not detriment the constitution rather it Iwill add the composite culture. ${ }^{15}$

Another Assamese intellectual and the former President of the Asom Sahitya Sabha (ASS) Tirtha Nath Sharma subscribing his view argued that unlike Sindhi, there was a substantial number of Nepali-speaking people, particularly in Darjeeling and Sikkim. He also maintained that like any other recognized language the origin of the Nepali language too was Sanskrit. ${ }^{16}$ Similarly, the former president of the Bodo Sahitya Sabha (BSS) Lakhyadhar Brahma also pleaded that the Nepalese had a fundamental right for their linguistic demand as the Sahitya Academy had duly recognized the same. ${ }^{17}$ Such memorable remarks of the Assamese intelligentsia obviously provided a great inspiration for the Nepali elite of Assam to further the cause of their linguistic demand. The Government of India however, in the long run realized the legitimacy and justification of 
linguistic demand of the Nepalese Community and therefore decided to incorporate Nepali language in the Eighth Schedule of the Constitution of India. As a result, the parliament of India accorded the demand for constitutional recognition of Nepali language along with Manipuri and Konkani on $20^{\text {th }}$ August, $1992 .{ }^{18}$ Thus, the dream of Gorkhas/Nepalese of India has come to be a reality due to the relentless efforts and determined attitude of the socio-cultural organizations of the Gorkhas .

\section{Conclusion:}

While summing up the discussion it ma be said that the Nepalese of Assam have been struggling to place their community at par with other forwarded section of population. For this purpose, the Nepali elite believed that certain constitutional status as indispensable. They included the recognition of Nepali language, status of Schedule Tribe and Caste, facilities for the cultivation and conservation of Nepali language and culture. Despite so, most of their demands have still remained unfulfilled but their efforts in this direction are still on.

\section{References:}

[1]. The term 'Gorkha' is a debatable since there is dearth of unanimity among the scholars whether the Nepalese and Gorkhas are the same race community or not. According to Byron Farwell- "Gorkhas are those people of Mongolian origin from tribes which British and Indian officers regard them as the military tribes or fighting class of Nepal who are enlisted and called by that name" (The Gorkhas, Penguin Books, London, 1984 p.12). Second Purushotam Banskota, a renowned historian of Tribhuvan University of Nepal opined that - There exist no Gorkha tribe, neither are all Nepalese entitled to be called Gurkhas. The term Applies collectively to those Nepalese who have served or are serving as mercenary soldiers in the British or Indian army..... predominantly among them were the Magar and the Gurungs of the western and central hills of Nepal (The Gurkhas Connection: A History of the Gurkha Recruitment in the British Indian Army, Nirala Publications, New Delhi, 1994, p.43). Thus, it is witnessed that all the Gurkhas are the Nepalese but all the Nepalese are not the Gurkhas. Hence, in the present context both the terms Gurkhas and Nepalese are, when needed, interchangeably used to mean the same people.

[2]. Reported in the 'Asomiya' (in Assam), May 31, 1947, cited in A. C. Bhuyan and S.P.De. (ed), ibid, p.320

[3]. Resolution of the Assam provincial Gurkha League adopted in its first Annual Conference held at Gauhati on December 31, 1946 and January 1, 1947

[4]. Assam Legislative Assembly Debate, Vol.1, No.5, $3^{\text {rd }}$ April, 1951, p1220

[5]. The Nepali Castes viz .Thapa,Gurung, Lama ,Mogor ,Newar ,Lohar ,Domai, Gaine, Rai, Chetri, Limbu, Sarki i.e.cobbler were recognized as other backward class (Govt.of Assam personnel (B) Dept. Office Memorandum NO-A BP338/83/14dated 4/1/1984

[6]. Memorandum of the AGS submitted to the Government of India on July 24, $1968^{\circ}$

[7]. The memorandum of the AANSU submitted to the Prime Minisster New Delhi on July 24, 1980

[8]. The resolution of the AGS adopted in the $18^{\text {th }}$ Annual Conference held at Margherita on $30^{\text {th }}$ December, 1984

[9]. A leaflet published by Amarjyoti Gogoi on behif of the United Reservation Movement Council of Assam dated April 21 ,1986

[10]. Mention maybe made that the editorial board of 'Jagrata Gorkha' a quarterly Nepali magazine consisting three members named Anand singh Thapa Birshingh Bhandari and Narendrashingha Rana submitted a memorandum to the president of India demanding inclusion of Nepali language into the constitution of India on January 18,1956 . The SMARIKA (SOUVENIR) of the $6^{\text {th }}$ Annual Conference of the All India Nepali Bhasa Samiti held at Nalbari on December 28, 1986, p. 36- 37

[11]. Suniti Kumar Chatterjee, 'Language and Litaerature of modern India', cited in Surya Das, Nepal, Nepali Aru Nepali, (SOUVENIR) of $6^{\text {th }}$ Annual conference of the AINBS held at Nalbari on December 28 1986, p. 65

[12]. The resolution adopted by the AAGS in its Annual Conference held at Tirap in Dibrugarh District on $8^{\text {th }}$ April, 1968

[13]. The memorandum of the AGS submitted to the Prime Minister of India New Delhi on January 20, 1972

[14]. The memorandum of the AANSU presented to the prime Minister of India, New Delhi on July 24, 1980

[15]. Appeared in the Assam Gurkha Sammelon Bulletin No.23,1979, p.8

[16]. Ibid., p,6

[17]. Ibid., p.8

[18]. Mention may be made that the AINBS has decided to observe August 20 th as Nepali Language Victory Day every year since 1992 onward on which day the Parliament of India passed the $77^{\text {th }}$ Constitutional Amendment Bill dealing with the constitutional reorganization of the Nepali language along with Manipuri and Konkani. (Reported in The Assam Tribune, September 20, 1992) 